\title{
Effect of Strain Rate on Hydrogen Embrittlement Susceptibility of Twinning-Induced Plasticity Steel Pre-charged with High-Pressure Hydrogen Gas
}

\author{
B. Bal ${ }^{\mathrm{a}, \mathrm{c}, *}$, M. Koyama ${ }^{\mathrm{a}}$, G. Gerstein ${ }^{\mathrm{b}}$, H. J. Maier ${ }^{\mathrm{b}}$, K. Tsuzaki ${ }^{\mathrm{a}}$ \\ aDepartment of Mechanical Engineering, Kyushu University, Nishi-ku, Fukuoka 819-0395, \\ Japan \\ beibniz Universität Hannover, Institut für Werkstoffkunde (Materials Science), An der \\ Universität 2, 30823 Garbsen, Germany \\ 'Department of Mechanical Engineering, Abdullah Gül University, 38039 Kayseri, Turkey
}

\begin{abstract}
The effects of tensile strain rate on the hydrogen-induced mechanical and microstructural features of a twinning-induced plasticity (TWIP) steel were investigated using a Fe-23Mn-0.5C steel with a saturated amount of hydrogen. To obtain a homogeneous hydrogen distribution, high-pressure hydrogen gas pre-charging was performed at $423 \mathrm{~K}$. Similar to previous studies on hydrogen embrittlement, the deterioration in the tensile properties became distinct when the strain rate was decreased from $0.6 \times 10^{-3}$ to $0.6 \times 10^{-4} \mathrm{~s}^{-1}$. In terms of microstructural features, hydrogen-precharging decreased the thickness of deformation twin plates, and it localized dislocation slip. Moreover, facets of the hydrogeninduced quasi-cleavage feature on the fracture surface became smoother with decreasing strain rate. In this study, we proposed that a combined effect of hydrogen segregation, slip localization, and thinning of twin plates causes the hydrogen embrittlement of TWIP steels, particularly at a low strain rate.
\end{abstract}

*Corresponding author. Department of Mechanical Engineering, Abdullah Gül University, 38039 Kayseri, Turkey. Tel.: +90 352290 8327; fax: +90 3523388828 .

E-mail address: burak.bal@agu.edu.tr (B. Bal). 
Keywords: Twinning-induced plasticity steels; Hydrogen embrittlement; Tension test; Quasicleavage fracture.

\section{Introduction}

Owing to the exceptional combination of mechanical properties, such as a high work hardening capability that allows a high tensile strength with significant ductility, austenitic Fe-Mn-C twinning-induced plasticity (TWIP) steels are attractive candidate materials for use in the automotive, defense, and mining industries [1]. The excellent mechanical properties of TWIP steel, which has a face-centered cubic (FCC) crystal structure at room temperature, have been subject of several studies [2-4], many of which revealed that the main features underlying the observed mechanical behavior are the presence of deformation twins and the occurrence of dynamic strain aging (DSA) [5,6]. Specifically, twin nucleation starts at the onset of plastic deformation and twin density increases during plastic deformation, forming $\Sigma 3$ twin boundaries, which reduce the mean free path of dislocations and act as strong obstacles against dislocation motion. In addition, DSA causes pinning of mobile dislocations, promoting the multiplication rate of dislocations. Twinning and DSA provide a sustained high work hardening capacity in TWIP steels, delaying plastic instability [7-10].

In the present context, it is important to note that the FCC structure provides for a low diffusion coefficient of hydrogen. Thus, austenitic steels have been noted as potential materials for hydrogen-related infrastructures because of the low hydrogen diffusivity $[11,12]$. Accordingly, the austenitic TWIP steels have been also suggested as structural materials to be used in hydrogen environments such as high-pressure hydrogen gas atmospheres in fuel vehicles [13]. However, it has also been reported that TWIP steels are vulnerable to hydrogen embrittlement (HE), which can cause sudden catastrophic failure [14-17]. Therefore, to broaden the field of applications to hydrogen-related infrastructures, understanding and 
improving the HE susceptibility performance of TWIP steels has become a critical problem that needs to be solved.

The HE susceptibility of different types of TWIP steels has been studied using different experimental methods including tensile and cup forming tests $[14,17-19,13]$ and indentation tests [20]. Previous studies have mostly focused on the effects of alloying elements [15,21,22], hydrogen content [23], grain size [24,25], precipitates [26], \& martensite [27], and coating layers [28] on the HE behavior of TWIP steels. Moreover, the effects of hydrogen on the fracture mode of TWIP steel has been well studied $[15,29]$. Consequently, in stable FeMn-C TWIP steels, the factors affecting the HE susceptibility are the formation of a surface layer, appearance of deformation twins, and occurrence of strain aging, causing the transition of the fracture mode from ductile to brittle $[15,21,30]$. However, in spite of the many works on the HE of TWIP steels, there are only a limited number of studies focusing on the effects of strain rate on HE with a focus on micro-scale deformation mechanisms. In austenitic steels including TWIP steels the hydrogen diffusivity is a key parameter, which is strongly correlated to the strain rate dependence of the susceptibility for hydrogen embrittlement. Therefore, the strain rate dependence of HE behavior in the TWIP steels is a crucial issue. To the best of the authors' knowledge, a detailed microstructure analysis of TWIP steels deformed at different strain rates after high-pressure hydrogen gas charging has never been conducted. Hence, metallographic investigations of the strain rate effect with the highpressure gas charging were conducted to shed light on an important aspect of the underlying HE mechanisms.

In this study, the effects of strain rate on the HE susceptibility of Fe-23Mn-0.5C TWIP steel charged with hydrogen gas were investigated by tensile testing at ambient temperature. Specifically, this study aims at clarifying the effects of strain rate on HE and associated 
microstructural effects. To elucidate the effects of strain rate, the microstructural investigations were conducted using in-situ scanning electron microscopy (SEM) and transmission electron microscopy (TEM).

\section{Experimental Details}

\subsection{Materials}

In the present study, an Fe-23Mn-0.5C (wt.-\%) TWIP steel was investigated, and its chemical composition is presented in Table 1. Prior to actual testing, the material was solution heat treated at $1273 \mathrm{~K}$ for $1 \mathrm{~h}$ and then water quenched. The average grain size of the samples was determined to be $23 \mu \mathrm{m}$ including the annealing twin boundaries, and no strong texture was present $($ Taylor factor $=3.01)$, as shown in Figure 1 .

Table 1. Chemical composition of the material studied (in wt.-\%)

\begin{tabular}{llllll}
\hline C & Si & Mn & P & S & Fe \\
\hline $\mathbf{0 . 5 1}$ & 0.27 & 22.6 & $<0.001$ & 0.0072 & Balance \\
& & & & & \\
\hline
\end{tabular}



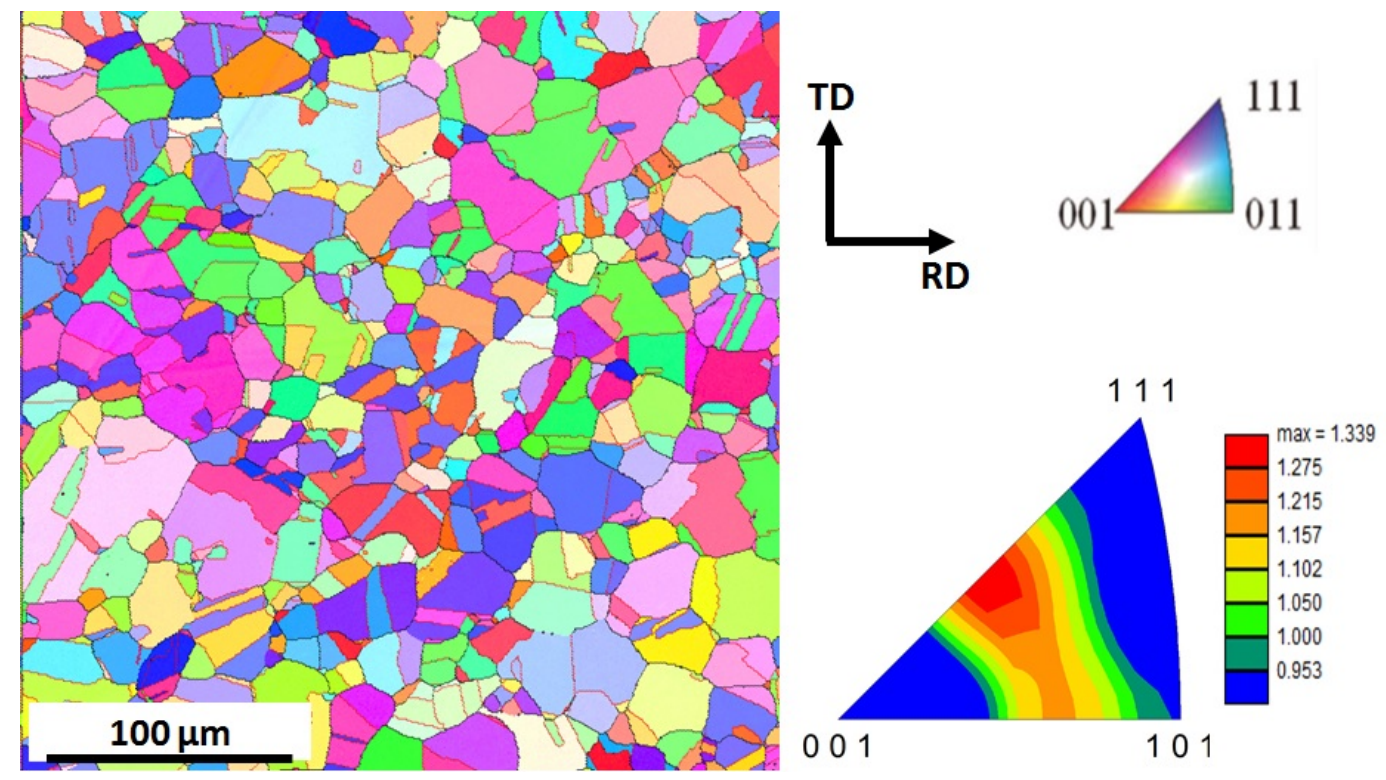

Figure 1. Rolling-direction (RD) inverse pole figure map (IPF) with a beam step size of $2 \mu \mathrm{m}$ showing the initial microstructure of the as-solution-treated specimen. (2-column)

To observe the hydrogen effect at different strain rates, one set of the $1 \mathrm{~mm}$ thick specimens were charged with hydrogen, and a second set was not exposed to hydrogen gas. All the hydrogen gas used in this study had a high purity of $99.999 \%$. The specimens were exposed to the hydrogen gas at a gas pressure of $7.3 \mathrm{MPa}$ at $423 \mathrm{~K}$ for 1 week. For these conditions, the comparison of the half thickness of the specimen with the calculated diffusion length of hydrogen revealed that the hydrogen distribution was sufficiently homogeneous throughout the thickness. The hydrogen desorption behavior was analyzed by thermal desorption spectroscopy (TDS) from room temperature to $873 \mathrm{~K}$ with a heating rate of 400 $\mathrm{K} / \mathrm{h}$. The cumulative diffusible hydrogen content of the samples was measured to be $5.58 \mathrm{wt}$. ppm (Figure 2). 


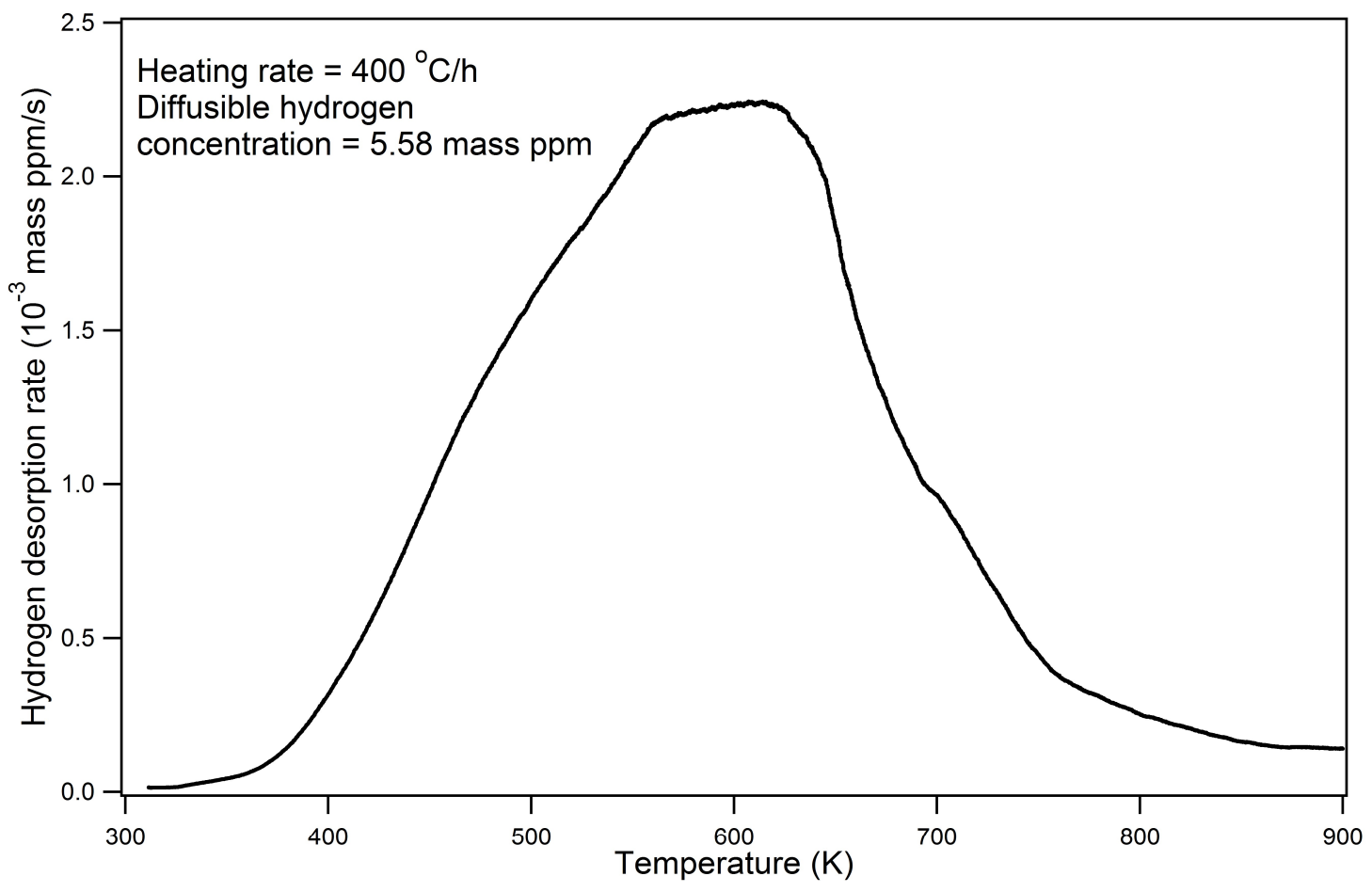

Figure 2. Hydrogen desorption rate profile of a hydrogen-charged specimen. (1-column)

\subsection{Tensile tests and associated microstructure characterization}

Tensile tests were conducted for the specimens with and without hydrogen pre-charging at quasi-static strain rates, namely at an initial strain rate of $0.6 \times 10^{-3}$ and $0.6 \times 10^{-4} \mathrm{~s}^{-1}$ at ambient temperature. These strain rates were chosen with the purpose of promoting HE with a simultaneous reduction in area by allowing the sweep of hydrogen by dislocations. The samples used for tensile testing were cut from the solution heat-treated material by electrodischarge machining with the dimensions shown in Fig. 3. 


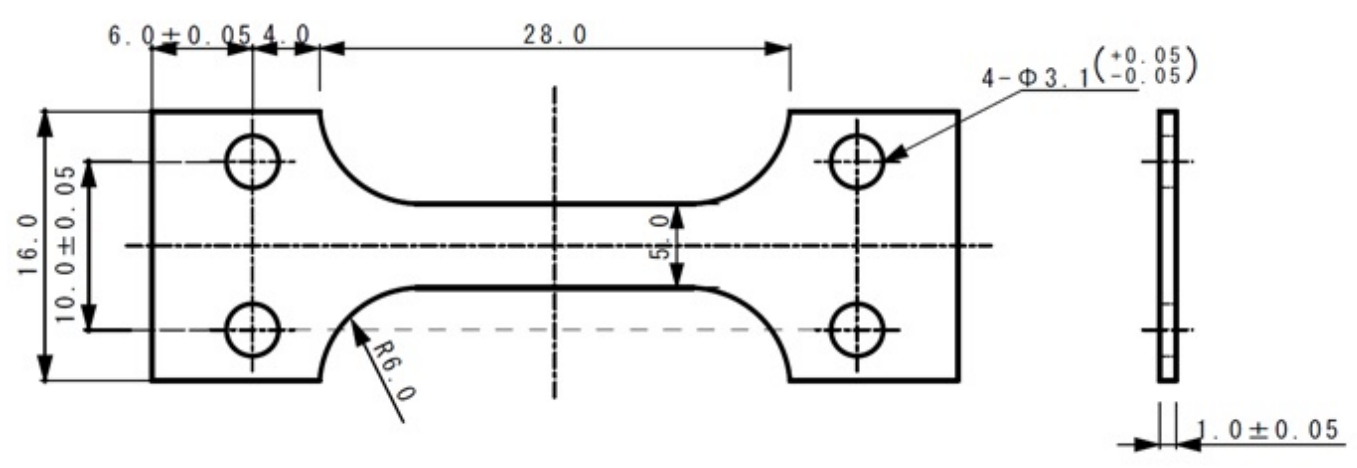

Figure 3. Specimen dimensions for tensile testing (unit: $\mathrm{mm})$. (1-column)

Complementary microstructural observations were conducted using SEM, TEM, and electron backscatter diffraction (EBSD) to characterize the fracture surface and microstructural details such as dislocations and twins. Furthermore, in-situ SEM observations were performed at an initial strain rate of $0.6 \times 10^{-4} \mathrm{~s}^{-1}$ in order to observe the effect of hydrogen on the resulting surface topography. For the TEM study, thin foils were extracted from the samples in the form of flat disks with a thickness of $400 \mu \mathrm{m}$. These disks were then mechanically thinned down to $80 \mu \mathrm{m}$ and electropolished on both sides by conventional twinjet electropolishing with an electrolyte consisting of $80 \mathrm{ml} 60 \%$ perchloric acid, $500 \mathrm{ml}$

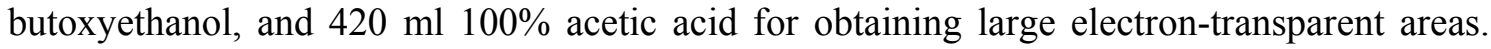
The electropolishing was conducted at $-12{ }^{\circ} \mathrm{C}$ under an acceleration voltage of $22.5 \mathrm{~V}$. The electropolishing procedure was used prior to EBSD analysis, which was conducted at $20 \mathrm{kV}$.

The dislocation density and the twin thickness were determined using the TEM images. Specifically, the dislocation density was calculated based on the total length of the projections of the dislocations onto the foil surface. The foil thickness was determined from the length of the mapped dislocations and the known inclination to the foil plane. Furthermore, the twin thickness was determined as the maximum thickness of a twin lamella, and was measured as the distance between two twin boundaries. 


\section{Results and discussion}

\subsection{Effects of strain rate and hydrogen charging on the stress-strain response}

Figure $4 \mathrm{a}$ shows the engineering stress-engineering strain curves with the corresponding tensile properties of the Fe-23Mn-0.5C TWIP steels with and without hydrogen charging at room temperature and different strain rates. The serrations in the stress-strain curves arise from DSA [6,9,31,32]; accordingly, a negative strain rate sensitivity of the flow stress associated with a reduction in probability of dislocation pinning by carbon [33] is observed. The specimens tested without prior hydrogen-charging did not show a pronounced strain rate dependence for elongation at failure. The hydrogen charging clearly deteriorates the elongation at failure, with the effect being more pronounced at the lower strain rate of $0.6 \times$ $10^{-4} \mathrm{~s}^{-1}$ (cf. inset to Fig. 4) The decrease in the tensile properties of TWIP steel upon hydrogen charging was also observed previously $[16,23]$. In addition, the effect of strain rate on the HE susceptibility has been reported earlier in conventional high strength steels $[34,35]$, but it has not been confirmed in Fe-Mn-C TWIP steels. In fact, only pre-strain rate dependence in TWIP steel before hydrogen charging has been reported previously [17].

The primary reason why the HE was more pronounced at the lower strain rate can be attributed to the fact that sufficiently low strain rates allow the hydrogen to interact with moving dislocations, which in turn promotes HE [36,37]. Figure $4 b$ shows the work hardening rate curves, which are important for identifying if the failure occurred by a fully ductile mechanism. The broken line indicates that the hydrogen-assisted failure does not satisfy the plastic instability condition, indicating that premature brittle fracture had occurred which is in accordance with previous observations on TWIP steel [9,38]. In the following sections, we 
show and discuss microstructural factors affecting the strain rate dependence of $\mathrm{HE}$ susceptibility. 

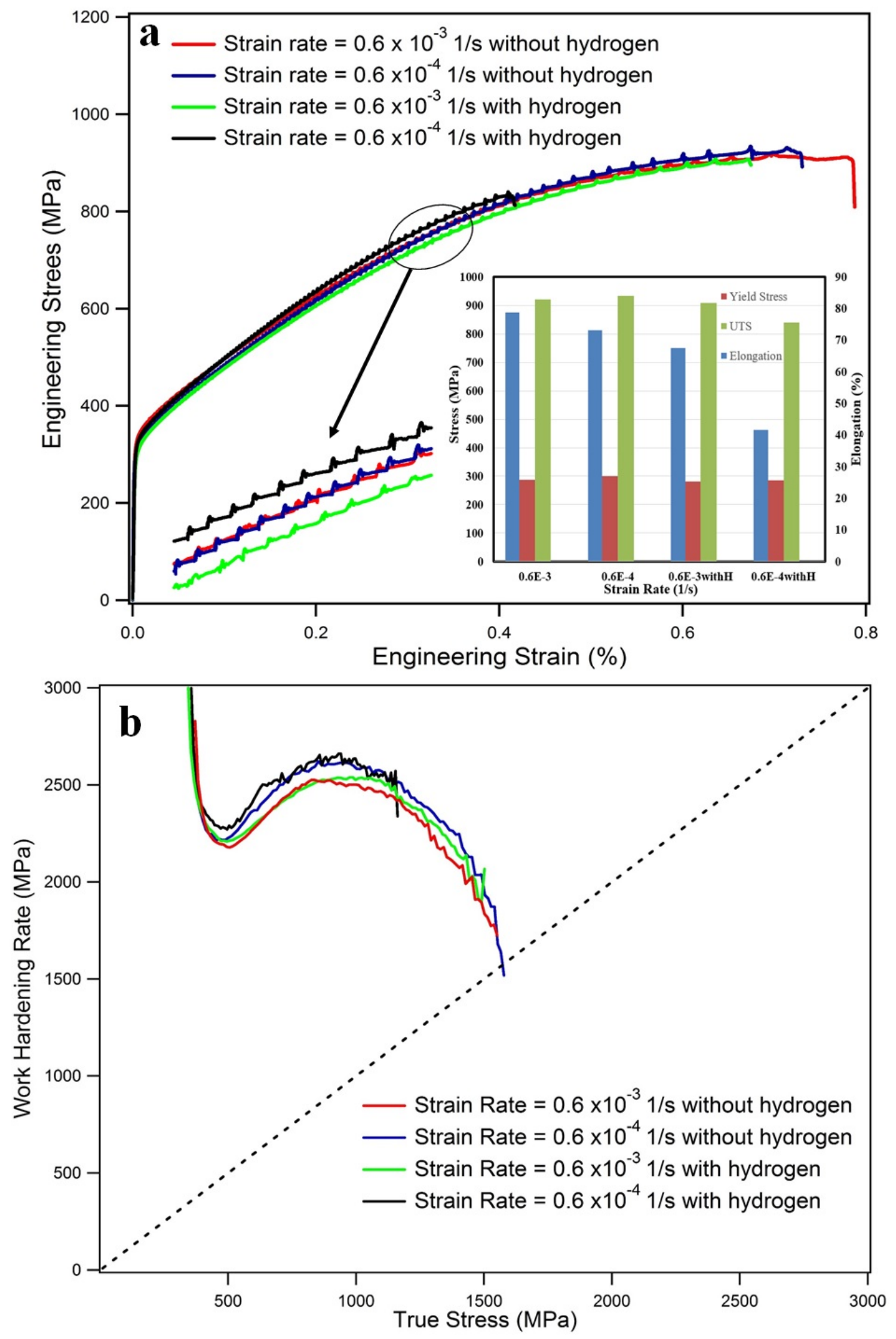
Figure 4. (a) Tensile behavior and (b) corresponding work hardening behavior of the Fe23Mn-0.5C TWIP steels with and without hydrogen charging at different strain rates. (1column)

\subsection{Characterization of fracture surfaces}

Figure $5 \mathrm{a}$ and $5 \mathrm{~b}$ show the fracture surfaces of specimens that were not charged with hydrogen at strain rates of $0.6 \times 10^{-4}$ and $0.6 \times 10^{-3} \mathrm{~s}^{-1}$, respectively. Figure $5 \mathrm{a} 1$ and $5 \mathrm{~b} 1$ are the magnified images of the highlighted zone in Figures 5a and 5b, respectively. Both samples showed fully ductile fracture surfaces with a well-developed dimple structure regardless of the actual strain rate.
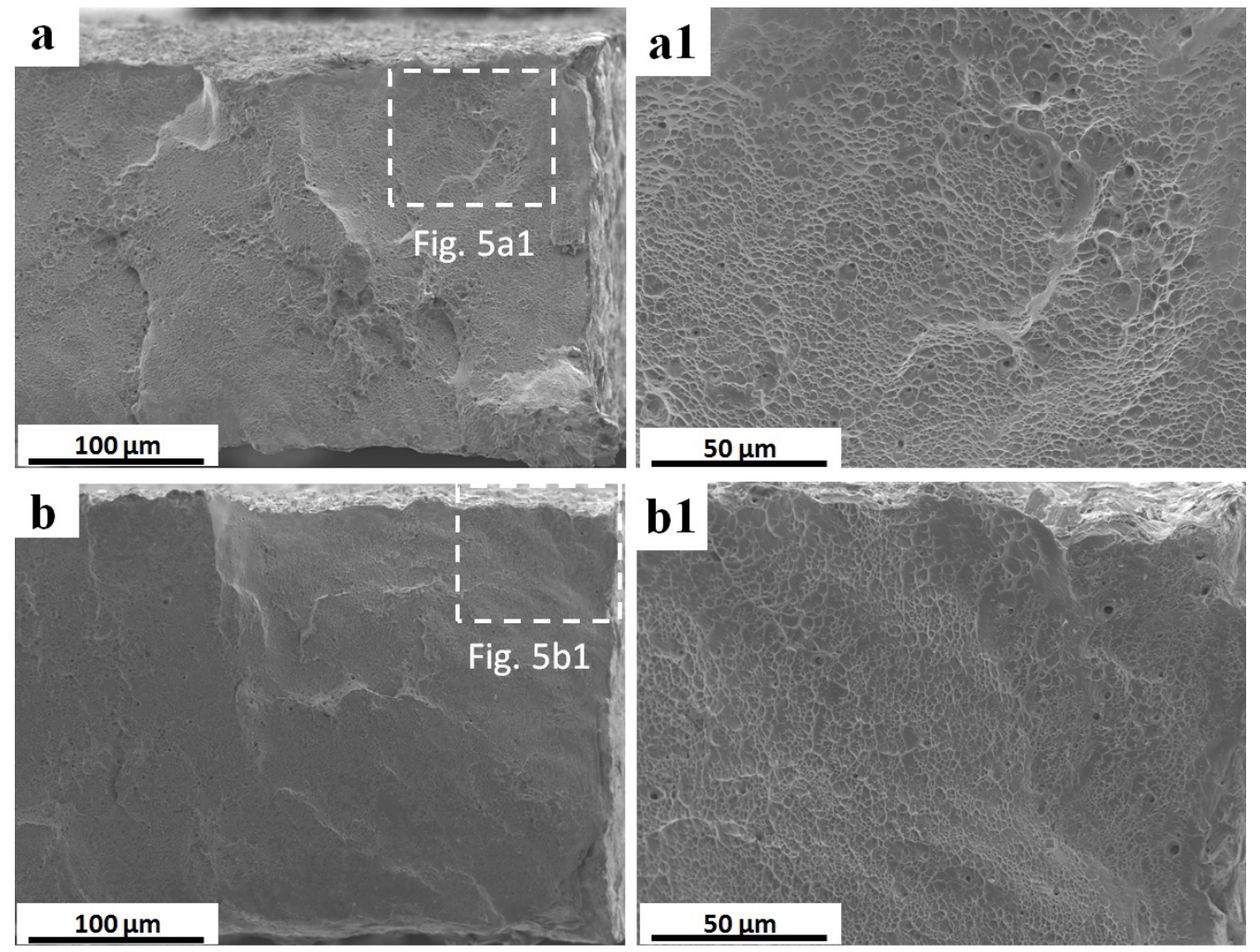

Figure 5. Fractographs of the specimen tested without prior hydrogen charging a) at $0.6 \times 10^{-}$ ${ }^{4} \mathrm{~s}^{-1}$ b) at $0.6 \times 10^{-3} \mathrm{~s}^{-1} \cdot(2$-column $)$ 
Figures $6 \mathrm{a}$ and $6 \mathrm{~b}$ show the fracture surfaces of the hydrogen-charged specimens at strain rates of $0.6 \times 10^{-4} \mathrm{~s}^{-1}$ and $0.6 \times 10^{-3} \mathrm{~s}^{-1}$, respectively. In Figure 6a, a quasi-cleavage feature is observed in the specimen. Figure 6al shows the magnified image of the area marked by the square in Figure 6a, revealing more distinct quasi-cleavage fracture. Clearly, the ductile fracture in Figure 6a transformed to quasi-static cleavage after hydrogen charging. This finding is consistent with the results obtained from previous studies on different materials and also TWIP steel [12,19,36,39-42]. In addition, as shown in Figure 6b, it can be observed that at the higher strain rate, cleavage is less pronounced. Moreover, the magnified image shown in Figure $6 \mathrm{~b} 1$ demonstrates that the quasi-cleavage facets are not as smooth when compared to the facets observed at the lower strain rate, which is probably because of the contribution of the ductile mechanism. The strain rate dependence of the hydrogeninduced quasi-cleavage feature corresponds to the degradation of tensile properties seen after hydrogen charging (cf. Fig. 4). The hydrogen-assisted quasi-cleavage cracking in TWIP steels has been reported to arise from twin boundary cracking $[43,44]$ or martensite-related boundary cracking [27]. Specifically, the boundary cracking modes stem from microstructural stress concentration $[45,46]$. Therefore, possible microstructural stress concentration sources are demonstrated through multi-probe microstructure characterization in section 3.3. 

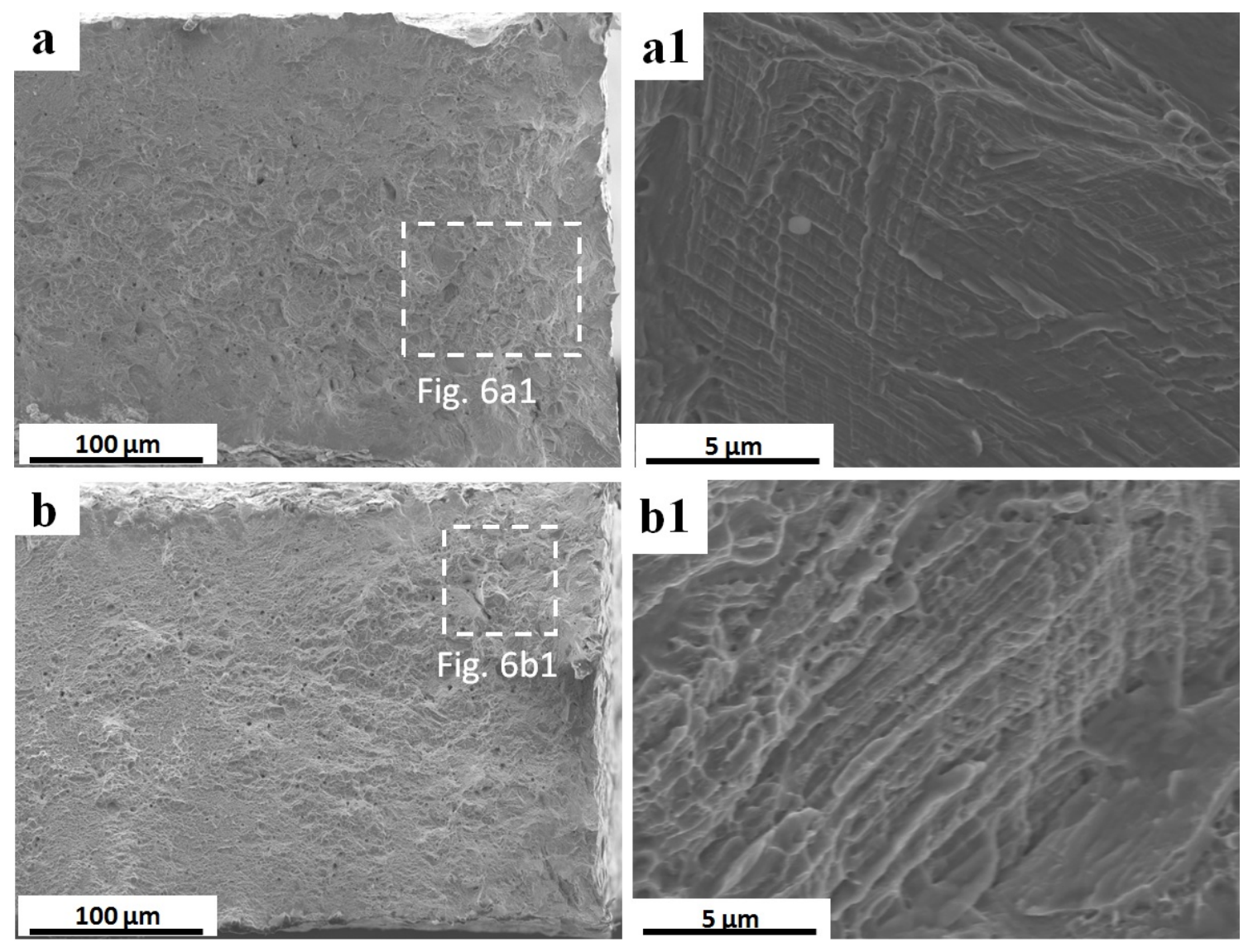

Figure 6. SEM surface fractographs of the hydrogen-charged specimen a) at $0.6 \times 10^{-4} \mathrm{~s}^{-1} \mathbf{b}$ ) at $0.6 \times 10^{-3} \mathrm{~s}^{-1} \cdot(2$-column $)$

\subsection{Effect of hydrogen on microstructure evolution for different strain rates}

In order to clarify the microstructural factors causing the hydrogen-assisted quasicleavage fracture and the associated strain rate effect, the microstructural stress concentration sources were identified through microstructural characterization as mentioned above. This revealed that $\varepsilon$ (hcp)- and $\alpha^{\prime}$ (bcc)- martensitic transformation was not present even after $30 \%$ deformation in both the uncharged and hydrogen-charged specimens. This is different from other TWIP steels with high HE susceptibility [27] and can be attributed to the increase in the stacking fault energy as a result of the high Mn concentration $[6,47,48]$. Consequently, martensite-related boundary cracking was ruled out as the HE mechanism in this study. In 
other words, twin boundary cracking is the primary phenomenon triggering HE, as reported for electrochemically hydrogen-charged steels [46].

TEM observations showed that the average dislocation densities of the specimens not charged with hydrogen at high strain rate was slightly less than that for the low strain rate, and the dislocation density around the highly dense dislocation region was measured as $8 \times 10^{13}$ $\mathrm{m}^{-2}$ and $3 \times 10^{14} \mathrm{~m}^{-2}$ at $0.6 \times 10^{-3} \mathrm{~s}^{-1}$ and $0.6 \times 10^{-4} \mathrm{~s}^{-1}$, respectively. The increase in dislocation density with decreasing strain rate is attributed to promotion of DSA $[49,50]$. In addition, TEM results for specimens strained to $30 \%$ showed that the average twin thickness in the specimens without hydrogen was less at $0.6 \times 10^{-4} \mathrm{~s}^{-1}(35 \mathrm{~nm})$ than the average twin thickness at $0.6 \times 10^{-3} \mathrm{~s}^{-1}(150 \mathrm{~nm})$. Therefore, microstructural stress concentration and strain hardening arising from subsequent slip-twin interactions at the lower strain rate was more significant than that in the higher strain rate case after 30\% deformation [51-53]. The effects of hydrogen charging on the evolution behavior of the dislocation density and the twin thickness are shown below.

Figure 7a shows the RD-IPF map for an uncharged specimen after testing at $0.6 \times 10^{-3} \mathrm{~s}^{-}$ ${ }^{1}$. In this case, the EBSD analyses were conducted with a beam step size of $200 \mathrm{~nm}$ to be able to detect twin plates, which is in accordance with a previous observation of TWIP steel [54]. Deformation twin bundles are observed in Figure 7a. Figure $7 \mathrm{~b}$ shows the corresponding TEM analyses, which indicates nano-twin formation inside previously formed twins. Nanotwin formation is commonly observed as discussed in previous studies on TWIP steels $[1,10,55]$, irrespective of strain rate and hydrogen-charging, and can be considered as a significant microstructural stress concentration source. Figure 8a shows the RD-IPF map for the hydrogen-charged specimen at $0.6 \times 10^{-3} \mathrm{~s}^{-1}$. When compared to the uncharged case, an increase in twin density is obvious which is in good agreement with previous studies on 
austenitic steels $[15,56,57]$. Figure $8 \mathrm{~b}$ shows the corresponding TEM analyses where the formation of two different twin variants is visible. Interestingly, the introduction of hydrogen decreased the average twin thickness but did not change the average dislocation density considerably $\left(5 \times 10^{13} \mathrm{~m}^{-2}\right.$ in both cases $)$. In particular, the average thickness of the primary twins and secondary twins in the specimens without hydrogen was $150 \mathrm{~nm}$ and $17 \mathrm{~nm}$, respectively, whereas, in the hydrogen-charged specimen the average thickness of the primary twins was $120 \mathrm{~nm}$ and that of the secondary twins was $14 \mathrm{~nm}$. The current result on the hydrogen effect on dislocation density is different from previous studies that had reported that the introduction of hydrogen increases the dislocation density in conventional steels $[58,59]$.

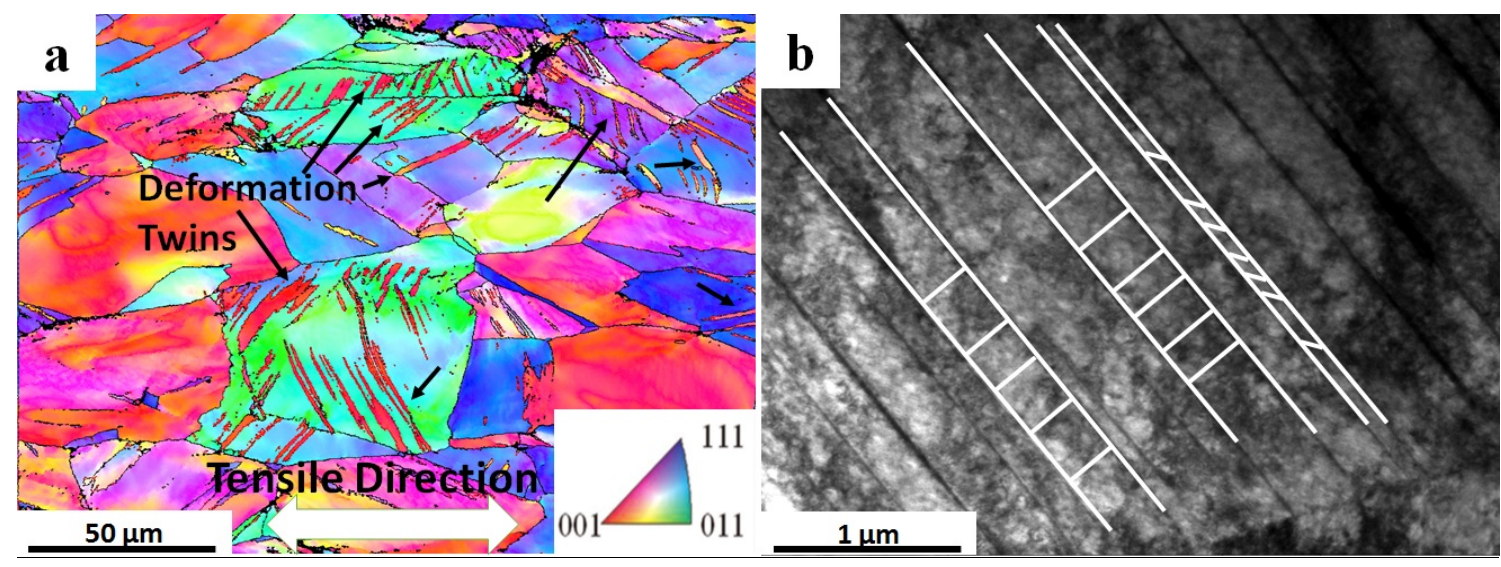

Figure 7. (a) RD IPF map and (b) TEM image of a specimen not charged with hydrogen after deformation to $30 \%$ at a strain rate of $0.6 \times 10^{-3} \mathrm{~s}^{-1}$. The beam step size was $0.2 \mu \mathrm{m}$.(2column) 

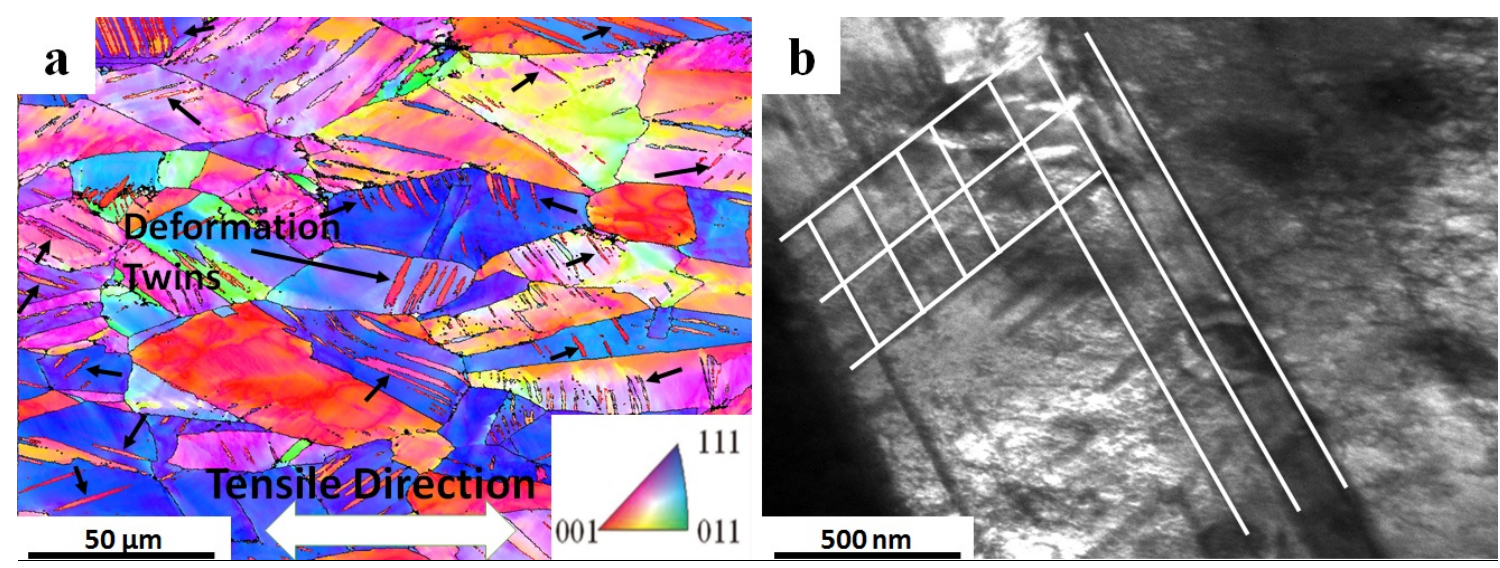

Figure 8. (a) RD IPF map and (b) TEM image of the hydrogen-charged specimen deformed $30 \%$ at $0.6 \times 10^{-3} \mathrm{~s}^{-1}$. The beam step size was $0.2 \mu \mathrm{m}$. (2-column)

Figure 9 shows a set of microstructure results of the hydrogen-uncharged Fe-23Mn-0.5C TWIP steel deformed to $30 \%$ strain at $0.6 \times 10^{-4} \mathrm{~s}^{-1}$. In Figure $9 \mathrm{a}$, twin bundles can be clearly seen similar to the $0.6 \times 10^{-3} \mathrm{~s}^{-1}$ case. In Figure $9 \mathrm{~b}$, the formation of a high dense dislocation wall (HDDW) acting as a barrier against dislocation motion is also observed. However, the subsequently formed deformation twin plates penetrate the HDDW as reported previously $[48,60]$, indicating that the stress concentration that occurs by interactions between a HDDW and deformation twinning is easily accommodated. From the TEM images, the dislocation density around the highly dense dislocation area and the average thickness of primary twins were determined as $3 \times 10^{14} \mathrm{~m}^{-2}$ and $35 \mathrm{~nm}$, respectively. In addition, the average thickness of secondary twins was determined as $12 \mathrm{~nm}$. Figures 9c and 9d show SEM images of the specimen surface prior to and after deformation to 30\%. In Figure 9d arrows and triangles mark multiple slip banding and void formation, respectively. At higher magnification (Fig. 9e) the slip line and voids are not only clearer, but it becomes also apparent that twining and slip impinge at grain or twin boundaries, which indicates accumulation of stress or plastic strain near the boundaries. The complex microstructure observed during deformation is in accordance with previous studies on TWIP steel [21,61-64] 


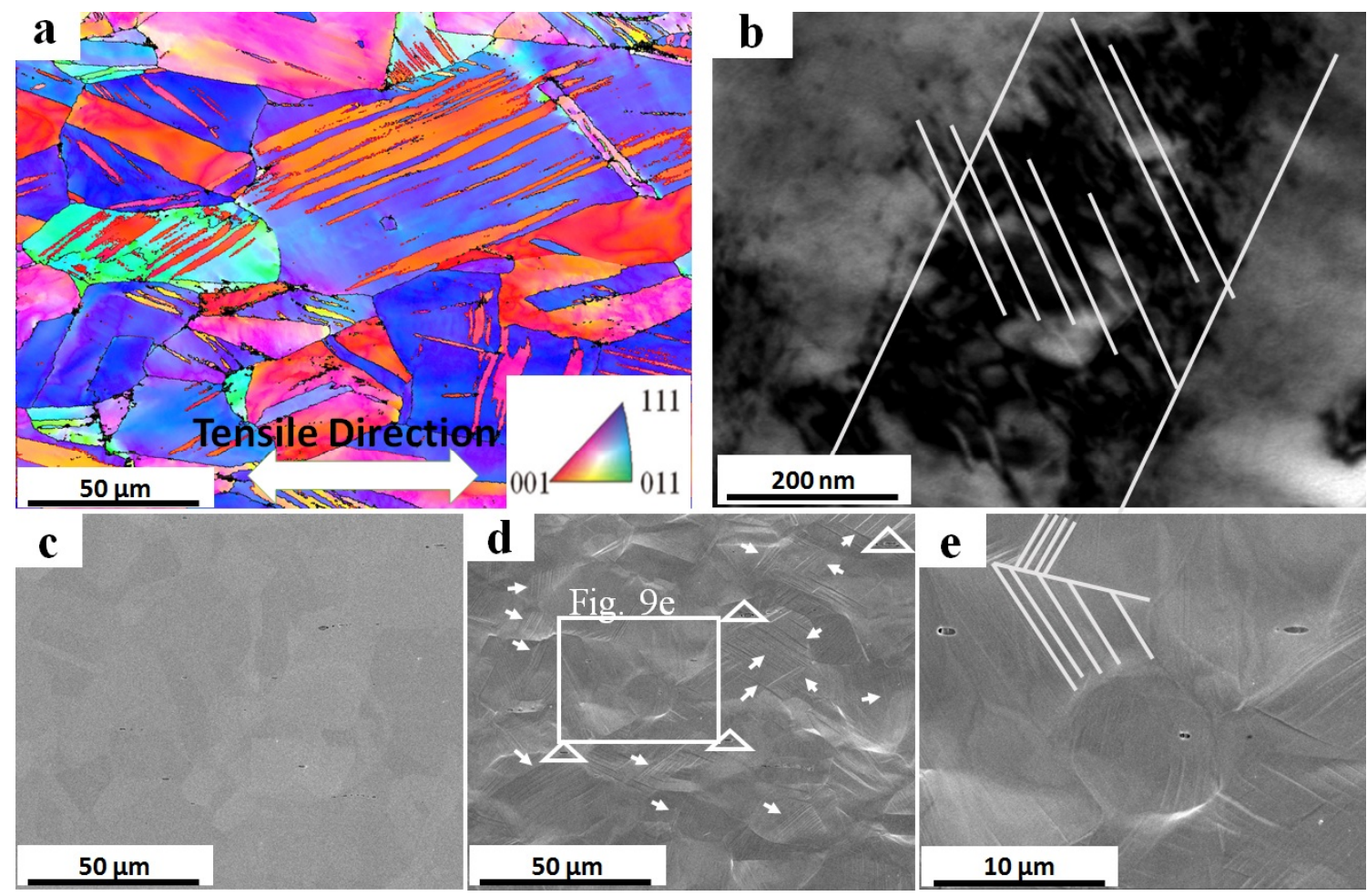

Figure 9. Microstructure evolution in an uncharged specimen: a) EBSD map after deformation to $30 \%$ at $0.6 \times 10^{-4} \mathrm{~s}^{-1}, \mathrm{~b}$ ) corresponding TEM micrograph c) SEM image prior to deformation, d) in-situ SEM image after 30\% deformation at $0.6 \times 10^{-4} \mathrm{~s}^{-1}$, e) magnified image of the section marked by the rectangle in Fig. 9d. (2-column)

Figure 10 a shows the corresponding set of microstructural observations for the hydrogen-charged Fe-23Mn-0.5C TWIP steel after tensile deformation to $30 \%$ along the tensile direction at $0.6 \times 10^{-4} \mathrm{~s}^{-1}$. In Figure 10a, the formation of twin bundles can be observed. In Figure 10b, the formation of dense dislocations and voids is visible. When compared to the uncharged case, hydrogen did not change the average dislocation density considerably but caused a decrease in the average twin thickness. Specifically, dislocation density and average thickness of primary twins were determined as $9 \times 10^{13} \mathrm{~m}^{-2}$ and $25 \mathrm{~nm}$, respectively. In addition, the average thickness of secondary twins was determined as $9 \mathrm{~nm}$. Even though enhanced microstructural interactions due to hydrogen were also observed in 
previous studies [59], an increased dislocation density with the introduction of hydrogen $[58,65,66]$, which would have indicated that the presence of hydrogen in the solid solution increases dislocation motion by decreasing the barriers to dislocation motion, was not observed in the current study. By contrast, comparison of the SEM images recorded prior to (Figure 10c) and after deformation (Figures 10d and 10e) demonstrates that hydrogen enhances the formation of slip bands, twins, and voids. The two twin variants that were observed throughout the microstructure are highlighted in Figure 10e.
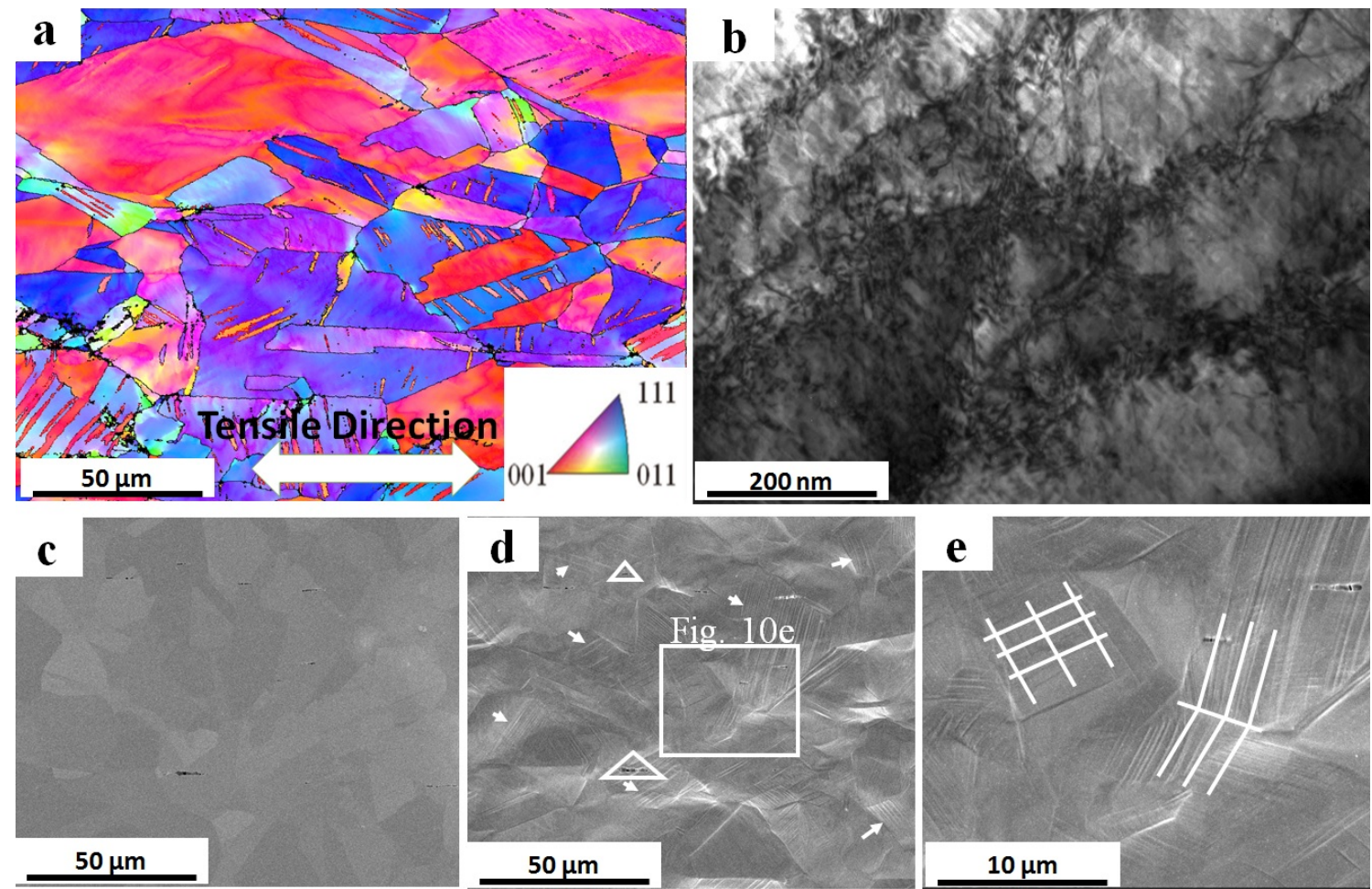

Figure 10. Microstructure evolution in a hydrogen-charged specimen deformed $30 \%$ at $0.6 \times$ $10^{-4} \mathrm{~s}^{-1}$. a) EBSD map after deformation to $30 \%$, b) corresponding TEM micrograph c) SEM image prior to deformation, d) in-situ SEM image after 30\% deformation, e) magnified image of the section marked by the rectangle in Fig. 10d. (2-column)

Figure 11 shows the microstructure of the uncharged and hydrogen-charged specimens at an earlier stage of deformation. Figure $11 \mathrm{a} 1$ and $11 \mathrm{~b} 1$ are the magnified images of the 
highlighted zone in Figure 11a and Figure 11b, respectively. The multi-scale images also show hydrogen-assisted slip processes already after $14 \%$ deformation, which can be attributed to the hydrogen enhanced localized plasticity (HELP) mechanism [67]. The difference in the slip activity becomes pronounced with increasing strain, as shown by the set of images in Figure 12, which indicates that hydrogen enhances the microstructural activities at all strain level according to the HELP mechanism.
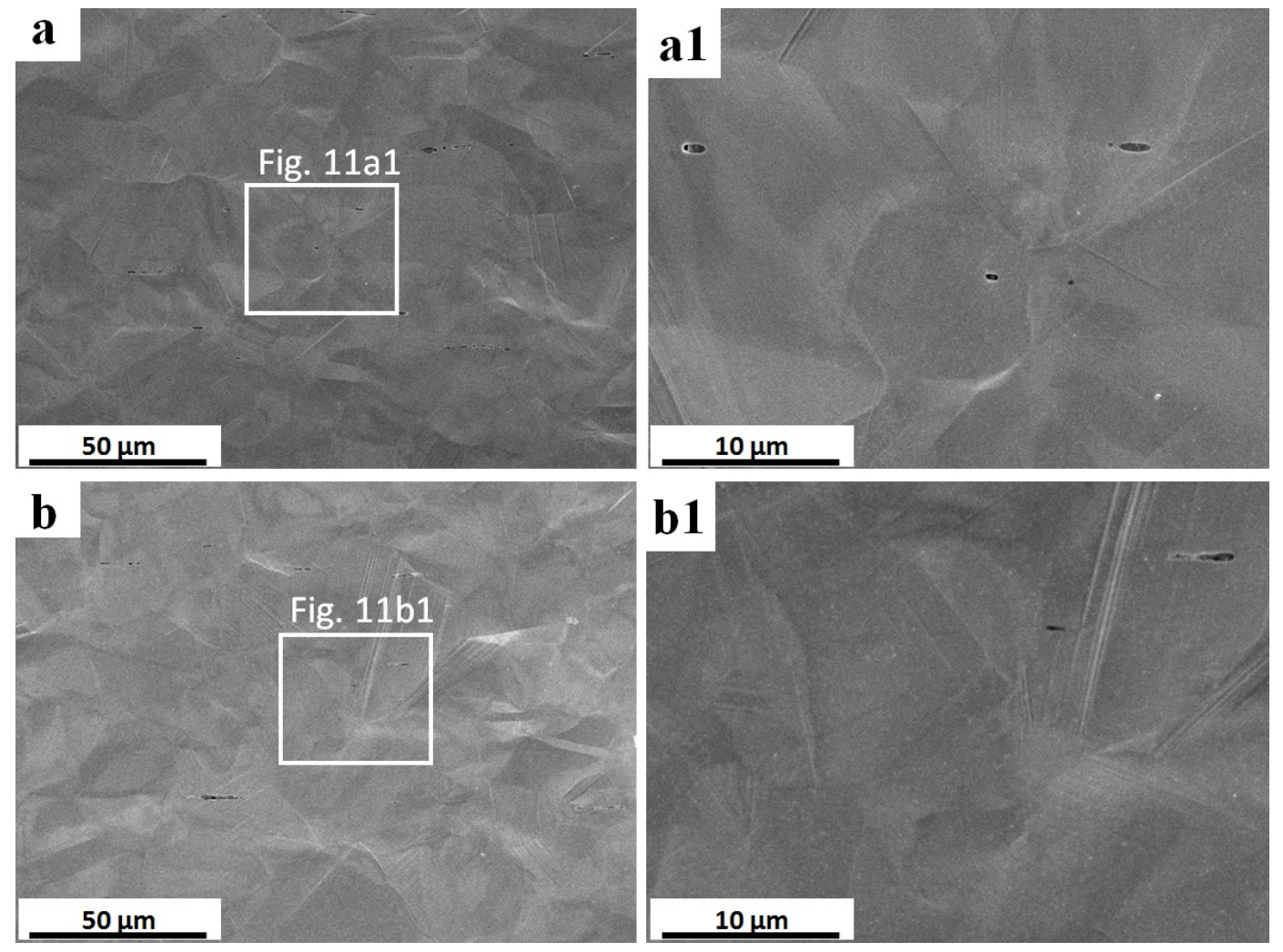

Figure 11. Microstructure as observed at $14 \%$ deformation and a strain rate of $0.6 \times 10^{-4} \mathrm{~s}^{-1}$ for a) an uncharged specimen and b) a hydrogen-charged specimen; figs. a1 and b1 provide higher magnification details of the areas marked by the rectangles. (2-column) 

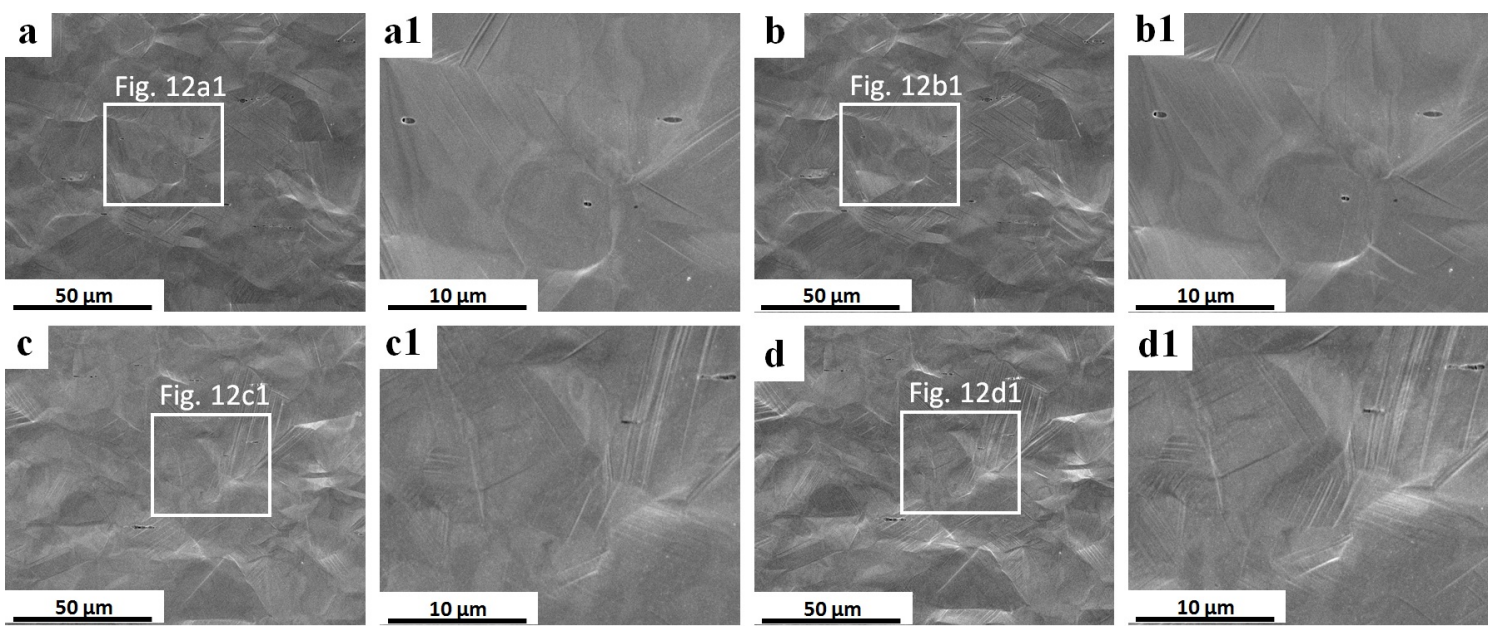

Figure 12. Microstructure evolution with strain; top row: uncharged specimen at a) $20 \%$ and

b) $25 \%$ strain; bottom row: hydrogen-charged specimen at c) $20 \%$ and d) $25 \%$ along with higher magnification details from the areas marked by the white rectangles; the strain rate was $0.6 \times 10^{-4} \mathrm{~s}^{-1}$ in all cases. (2-column)

\subsection{Proposed hydrogen embrittlement mechanism}

The microstructure observations revealed that hydrogen charging increased microstructural activities and at the same time led to a decrease in twin thickness. Moreover, in this steel the primary cause of HE is twin boundary cracking, which was suppressed upon an increase in strain rate. These features were enhanced by a decreasing strain rate. Based on these observations, the HE mechanism summarized in Fig. 13 is proposed, which also accounts for the strain rate dependence.

In Figure 13, schematic representation of our proposed model, a primary twin boundary forms first (step 1). This is promoted by the hydrogen charging. Next, the primary twin boundary gets distorted by hydrogen-enhanced slip and secondary twinning (step 2). The slip activity causing the distortion is enhanced by decreasing the strain rate because of the competitive motion of dislocations and diffusible hydrogen. Although hydrogen cannot 
segregate on the coherent $\Sigma 3$ twin boundary [68], distorted twin boundaries such as the corner of steps can trap hydrogen $[69,70]$ (step 3). In particular, at a low strain rate, hydrogendecorated dislocation motion delivers hydrogen to the twin boundary. The subsequently formed secondary twins and nano-twins in the pre-existing primary twin and the slip dislocation pile-up cause microstructural stress concentration on the twin boundary (step 4). Specifically, the microstructural stress concentration increases by hydrogen charging and decreasing strain rate because of the reduction in twin thickness [52,71]. In particular, thinner twins decrease the effective mean free path of dislocations more when compared to thicker twins and result in a higher microstructural stress concentration $[8,72,73]$. When the stress concentration cannot be accommodated plastically because of a reduction in the cohesive energy resulting from the presence of hydrogen, twin boundary cracking occurs (step 5). Since the cohesive energy depends on the segregated hydrogen content on the twin boundary, the delivery of hydrogen by the strain-rate dependent hydrogen decorated dislocation motion is crucial. More specifically, since a high amount of hydrogen is delivered by a dislocation at a low strain rate, the quasi-cleavage facets become sharper as compared to the high strain rate case, cf. Figure 6 , and the fracture mode changes to quasi-cleavage, particularly at a low strain rate. 


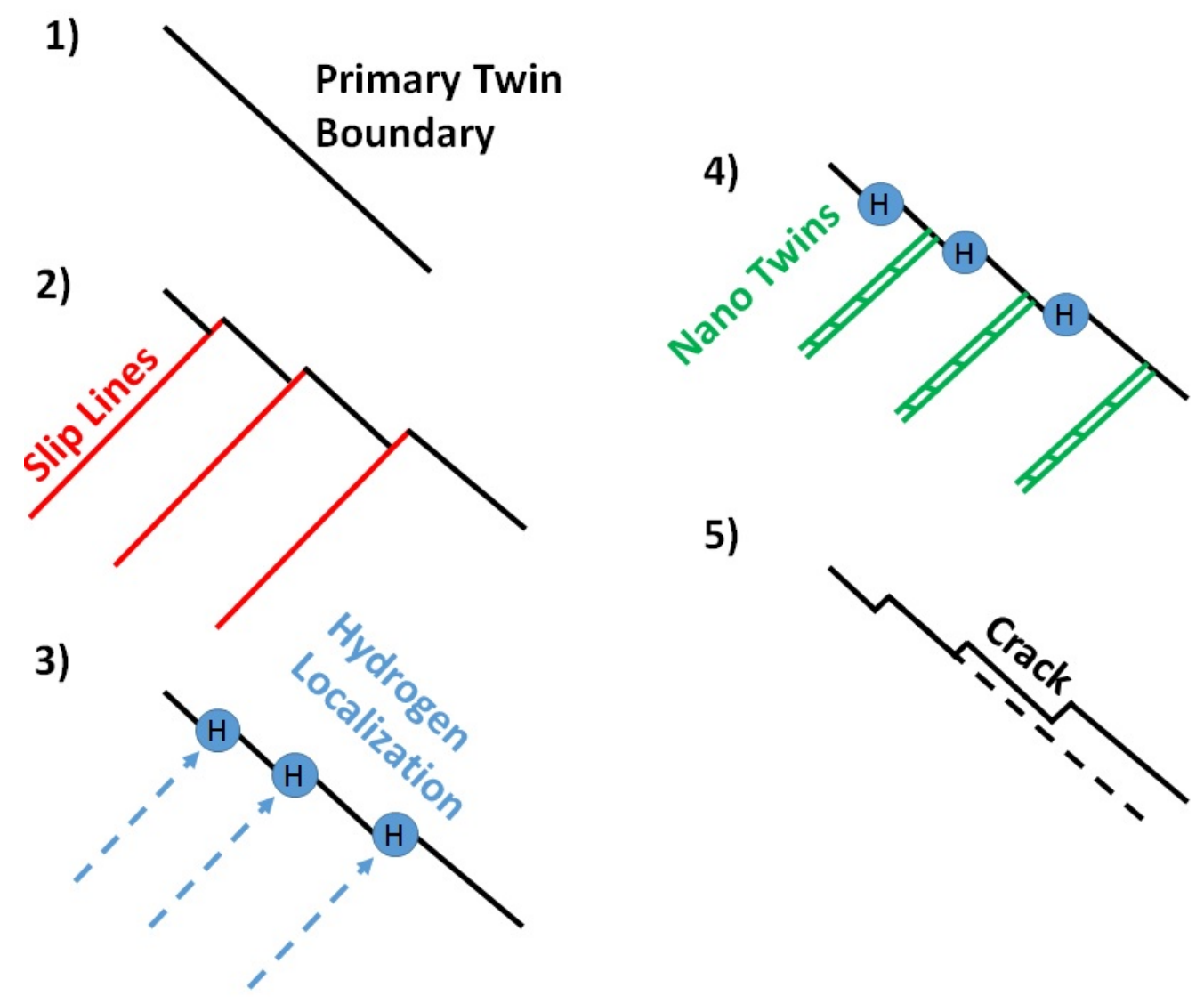

Figure 13. Schematic representation of the fracture process resulting in quasi-cleavage and embrittlement upon hydrogen charging of the TWIP steel studied. (1-column)

\section{Conclusion}

In this study, the effects of strain rate on the susceptibility for embrittlement of Fe23Mn-0.5C TWIP steel charged with hydrogen gas were investigated by tensile testing at ambient temperature. The strain rates chosen were $0.6 \times 10^{-3}$ and $0.6 \times 10^{-4} \mathrm{~s}^{-1}$. From the work presented herein the following conclusions can be drawn:

1) Hydrogen embrittlement is substantially more pronounced at low strain rates.

2) Hydrogen enhances the microstructural interactions, which contribute to the strain hardening mechanism of TWIP steel, i.e. slip formation and slip-twin interactions. Twin-slip 
interactions contributed to strain hardening more at low strain rates because of thinner twins. However, the introduction of hydrogen did not change the average dislocation density considerably.

3) Twin boundaries get distorted by hydrogen-enhanced microstructural activities, which are more pronounced at a low strain rate. The corner of the distorted twin boundaries traps hydrogen and promotes twin boundary cracking due to microstructural stress concentration at the twin boundary.

4) Hydrogen charging changes the fracture mode from ductile to quasi-cleavage at a low strain rate. However, less cleavage was observed at high strain rates.

\section{Acknowledgements}

This study was supported by the Grant-in-Aid for Young Scientists B (Grant Number 15K18235) and the Japan Science and Technology Agency (JST) (grant number: 20100113) under Industry-Academia Collaborative R\&D Program "Heterogeneous Structure Control: Towards Innovative Development of Metallic Structural Materials".

\section{References}

[1] Bal B, Gumus B, Gerstein G, Canadinc D, Maier HJ. On the micro-deformation mechanisms active in high-manganese austenitic steels under impact loading. Mater Sci Eng A 2015;632:29-34. doi:10.1016/j.msea.2015.02.054.

[2] Bouaziz O, Allain S, Scott CP, Cugy P, Barbier D. High manganese austenitic twinning induced plasticity steels: A review of the microstructure properties relationships. Curr Opin Solid State Mater Sci 2011;15:141-68. doi:10.1016/j.cossms.2011.04.002.

[3] Rahman KM, Vorontsov VA, Dye D. The effect of grain size on the twin initiation 
stress in a TWIP steel. Acta Mater 2015;89:247-57.

doi:10.1016/j.actamat.2015.02.008.

[4] Gumus B, Bal B, Gerstein G, Canadinc D, Maier HJ. Twinning activity in highmanganese austenitic steels under high velocity loading. Mater Sci Technol 2016;32:463-5. doi:10.1179/1743284715Y.0000000111.

[5] Lee T, Koyama M, Tsuzaki K, Lee YH, Lee CS. Tensile deformation behavior of FeMn-C TWIP steel with ultrafine elongated grain structure. Mater Lett 2012;75:169-71. doi:10.1016/j.matlet.2012.02.012.

[6] Koyama M, Sawaguchi T, Lee T, Lee CS, Tsuzaki K. Work hardening associated with $\varepsilon$-martensitic transformation, deformation twinning and dynamic strain aging in $\mathrm{Fe}$ 17Mn-0.6C and Fe-17Mn-0.8C TWIP steels. Mater Sci Eng A 2011;528:7310-6. doi:10.1016/j.msea.2011.06.011.

[7] Dumay A, Chateau J-P, Allain S, Migot S, Bouaziz O. Influence of addition elements on the stacking-fault energy and mechanical properties of an austenitic $\mathrm{Fe}-\mathrm{Mn}-\mathrm{C}$ steel. Mater Sci Eng A 2008;483-484:184-7. doi:10.1016/j.msea.2006.12.170.

[8] Bouaziz O, Allain S, Scott C. Effect of grain and twin boundaries on the hardening mechanisms of twinning-induced plasticity steels. Scr Mater 2008;58:484-7. doi:10.1016/j.scriptamat.2007.10.050.

[9] Koyama M, Sawaguchi T, Tsuzaki K. TWIP Effect and Plastic Instability Condition in an Fe-Mn-C Austenitic Steel. ISIJ Int 2013;53:323-9. doi:10.2355/isijinternational.53.323.

[10] Gumus B, Bal B, Gerstein G, Canadinc D, Maier HJ, Guner F, et al. Twinning activity in high-manganese austenitic steels under high velocity loading. Mater Sci Eng A 
2015;648:104-12. doi:10.1179/1743284715Y.0000000111.

[11] San Marchi C, Somerday BP, Tang X, Schiroky GH. Effects of alloy composition and strain hardening on tensile fracture of hydrogen-precharged type 316 stainless steels. Int J Hydrogen Energy 2008;33:889-904. doi:10.1016/j.ijhydene.2007.10.046.

[12] Tsuzaki K, Fukuda K, Koyama M, Matsunaga H. Hexagonal close-packed Martensiterelated Fatigue Crack Growth under the Influence of Hydrogen: Example of Fe-15Mn10Cr-8Ni-4Si Austenitic Alloy. Scr Mater 2016;113:6-9.

doi:10.1016/j.scriptamat.2015.10.016.

[13] Michler T, San Marchi C, Naumann J, Weber S, Martin M. Hydrogen environment embrittlement of stable austenitic steels. Int J Hydrogen Energy 2012;37:16231-46. doi:10.1016/j.ijhydene.2012.08.071.

[14] Mittal SC, Prasad RC, Deshmukh MB. Effect of Hydrogen on Fracture of Austenitic Fe-Mn-Al Steel. ISIJ Int 1994;34:211-6. doi:10.1017/CBO9781107415324.004.

[15] Dieudonné T, Marchetti L, Wery M, Chêne J, Allely C, Cugy P, et al. Role of copper and aluminum additions on the hydrogen embrittlement susceptibility of austenitic FeMn-C TWIP steels. Corros Sci 2014;82:218-26. doi:10.1016/j.corsci.2014.01.022.

[16] Koyama M, Akiyama E, Tsuzaki K. Hydrogen embrittlement in a Fe -Mn-C ternary twinning-induced plasticity steel. Corros Sci 2012;54:1-4. doi:10.1016/j.corsci.2011.09.022.

[17] Koyama M, Akiyama E, Tsuzaki K. Hydrogen-induced delayed fracture of a Fe-22Mn0.6C steel pre-strained at different strain rates. Scr Mater 2012;66:947-50. doi:10.1016/j.scriptamat.2012.02.040. 
[18] Chin K, Kang C, Yong S, Hong S, Lee S, Seop H, et al. Effects of Al addition on deformation and fracture mechanisms in two high manganese TWIP steels. Mater Sci Eng A 2011;528:2922-8. doi:10.1016/j.msea.2010.12.085.

[19] Lee SM, Park IJ, Jung JG, Lee YK. The effect of Si on hydrogen embrittlement of Fe18Mn-0.6C-xSi twinning-induced plasticity steels. Acta Mater 2016;103:264-72. doi:10.1016/j.actamat.2015.10.015.

[20] Han DK, Kim YM, Han HN, Bhadeshia HKDH, Suh DW. Hydrogen and aluminium in high-manganese twinning-induced plasticity steel. Scr Mater 2014;80:9-12. doi:10.1016/j.scriptamat.2014.01.039.

[21] Park IJ, Jeong KH, Jung JG, Lee CS, Lee YK. The mechanism of enhanced resistance to the hydrogen delayed fracture in Al-added Fe-18Mn-0.6C twinning-induced plasticity steels. Int J Hydrogen Energy 2012;37:9925-32. doi:10.1016/j.ijhydene.2012.03.100.

[22] Kwon YJ, Lee T, Lee J, Chun YS, Lee CS. Role of Cu on hydrogen embrittlement behavior in Fe-Mn-C-Cu TWIP steel. Int J Hydrogen Energy 2015;40:7409-19. doi:10.1016/j.ijhydene.2015.04.022.

[23] Koyama M, Akiyama E, Tsuzaki K. Effect of hydrogen content on the embrittlement in a Fe-Mn-C twinning-induced plasticity steel. Corros Sci 2012;59:277-81. doi:10.1016/j.corsci.2012.03.009.

[24] Bai Y, Momotani Y, Chen MC, Shibata A, Tsuji N. Effect of grain refinement on hydrogen embrittlement behaviors of high-Mn TWIP steel. Mater Sci Eng A 2016;651:935-44. doi:10.1016/j.msea.2015.11.017.

[25] Zan N, Ding H, Guo X, Tang Z, Bleck W. Effects of grain size on hydrogen 
embrittlement in a Fe-22Mn-0.6C TWIP steel. Int J Hydrogen Energy 2015;40:1068796. doi:10.1016/j.ijhydene.2015.06.112.

[26] Park IJ, Jo SY, Kang M, Lee SM, Lee YK. The effect of Ti precipitates on hydrogen embrittlement of Fe-18Mn-0.6C-2Al-xTi twinning-induced plasticity steel. Corros Sci 2014;89:38-45. doi:10.1016/j.corsci.2014.08.005.

[27] Chun YS, Kim JS, Park KT, Lee YK, Lee CS. Role of $\varepsilon$ martensite in tensile properties and hydrogen degradation of high-Mn steels. Mater Sci Eng A 2012;533:87-95. doi:10.1016/j.msea.2011.11.039.

[28] Jeon H-H, Lee S-M, Han J, Park I-J, Lee Y-K. The effect of Zn coating layers on the hydrogen embrittlement of hot-dip galvanized twinning-induced plasticity steel. Corros Sci 2016. doi:10.1016/j.corsci.2016.05.014.

[29] Chun YS, Lee J, Bae M, Park K, Soo C. Caliber-rolled TWIP steel for high-strength wire rods with enhanced hydrogen-delayed fracture resistance. Scr Mater 2012;67:6814. doi:10.1016/j.scriptamat.2012.07.006.

[30] Kim Y, Kang N, Park Y, Choi I, Kim G, Kim S, et al. Effects of the strain induced martensite transformation on the delayed fracture for Al-added TWIP steel. J Korean Inst Met Mater 2008;46:780-7.

[31] Lee S-J, Kim J, Kane SN, Cooman BC De. On the origin of dynamic strain aging in twinning-induced plasticity steels. Acta Mater 2011;59:6809-19. doi:10.1016/j.actamat.2011.07.040.

[32] Bal B, Gumus B, Canadinc D. Incorporation of dynamic strain aging into a ViscoPlastic Self-Consistent model for predicting the negative strain rate sensitivity of Hadfield steel. J Eng Mater Technol 2016;138:1-8. doi:10.1115/1.4033072. 
[33] Canadinc D, Efstathiou C, Sehitoglu H. On the negative strain rate sensitivity of Hadfield steel. Scr Mater 2008;59:1103-6. doi:10.1016/j.scriptamat.2008.07.027.

[34] Wang M, Akiyama E, Tsuzaki K. Crosshead speed dependence of the notch tensile strength of a high strength steel in the presence of hydrogen. Scr Mater 2005;53:713-8. doi:10.1016/j.scriptamat.2005.05.014.

[35] Krom AHM, Maier HJ, Koers RWJ, Bakker A. The effect of strain rate on hydrogen distribution in round tensile specimens. Mater Sci Eng A 1999;271:22-30. doi:10.1016/S0921-5093(99)00276-2.

[36] Michler T, Naumann J. Hydrogen environment embrittlement of austenitic stainless steels at low temperatures. Int J Hydrogen Energy 2008;33:2111-22. doi:10.1016/j.ijhydene.2008.02.021.

[37] Birnbaum HK. Hydrogen effects on deformation-relation between dislocation behavior and the macroscopic stress-strain behavior. Scr Metall 1994;31:149-53.

[38] Chen L, Kim H-S, Kim S-K, De Cooman BC. Localized Deformation due to PortevinLeChatelier Effect in 18Mn-0.6C TWIP Austenitic Steel. ISIJ Int 2007;47:1804-12. doi:10.2355/isijinternational.47.1804.

[39] Zhao J, Jiang Z, Lee CS. Effects of tungsten on the hydrogen embrittlement behaviour of microalloyed steels. Corros Sci 2014;82:380-91. doi:10.1016/j.corsci.2014.01.042.

[40] Djukic MB, Zeravcic VS, Bakic G, Sedmak A, Rajicic B. Hydrogen Embrittlement of Low Carbon Structural Steel. Procedia Mater Sci 2014;3:1167-72. doi:10.1016/j.mspro.2014.06.190.

[41] Martin ML, Fenske JA, Liu GS, Sofronis P, Robertson IM. On the formation and 
nature of quasi-cleavage fracture surfaces in hydrogen embrittled steels. Acta Mater 2011;59:1601-6. doi:10.1016/j.actamat.2010.11.024.

[42] Sasaki D, Koyama M, Noguchi H. Factors affecting Hydrogen-assisted cracking in a commercial tempered martensitic steel: Mn segregation, $\mathrm{MnS}$, and the stress state around abnormal cracks. Mater Sci Eng A 2015;640:72-81. doi:10.1016/j.msea.2015.05.083.

[43] Koyama M, Akiyama E, Sawaguchi T, Raabe D, Tsuzaki K. Hydrogen-induced cracking at grain and twin boundaries in an Fe-Mn-C austenitic steel. Scr Mater 2012;66:459-62. doi:10.1016/j.scriptamat.2011.12.015.

[44] Ryu JH, Kim SK, Lee CS, Suh D-W, Bhadeshia HKDH. Effect of aluminium on hydrogen-induced fracture behaviour in austenitic Fe-Mn-C steel. Proc R Soc A Math Phys Eng Sci 2012;469:20120458-20120458. doi:10.1098/rspa.2012.0458.

[45] Koyama M, Okazaki S, Sawaguchi T, Tsuzaki K. Hydrogen Embrittlement Susceptibility of Fe-Mn Binary Alloys with High Mn Content: Effects of Stable and Metastable $\varepsilon$-Martensite, and Mn Concentration. Metall Mater Trans A 2016;47:265673. doi:10.1007/s11661-016-3431-9.

[46] Koyama M, Akiyama E, Tsuzaki K, Raabe D. Hydrogen-assisted failure in a twinninginduced plasticity steel studied under in situ hydrogen charging by electron channeling contrast imaging. Acta Mater 2013;61:4607-18. doi:10.1016/j.actamat.2013.04.030.

[47] Koyama M, Springer H, Merzlikin S V., Tsuzaki K, Akiyama E, Raabe D. Hydrogen embrittlement associated with strain localization in a precipitation-hardened $\mathrm{Fe}-\mathrm{Mn}-$ Al-C light weight austenitic steel. Int J Hydrogen Energy 2014;39:4634-46. doi:10.1016/j.ijhydene.2013.12.171. 
[48] Gutierrez-Urrutia I, Raabe D. Dislocation and twin substructure evolution during strain hardening of an Fe-22wt.\% Mn-0.6wt.\% C TWIP steel observed by electron channeling contrast imaging. Acta Mater 2011;59:6449-62. doi:10.1016/j.actamat.2011.07.009.

[49] Owen WS, Grujicic M. Strain aging of austenitic hadfield manganese steel. Acta Mater $1999 ; 47: 111-26$.

[50] Soare MA, Curtin WA. Single-mechanism rate theory for dynamic strain aging in fcc metals. Acta Mater 2008;56:4091-101. doi:10.1016/j.actamat.2008.04.030.

[51] Karaman I, Sehitoglu H, Beaudoin AJ, Chumlyakov YI, Maier HJ, Tome CN. Modeling the deformation behavior of hadfield steel single and polycrystals due to twinning and slip. Acta Mater 2000;48:2031-47.

[52] Karaman I, Sehitoglu H, Chumlyakov Y., Maier HJ, Kireeva IV. The effect of twinning and slip on the bauschinger effect of hadfield steel single crystals. Metall Mater Trans A 2001;32:695-706.

[53] Canadinc D, Karaman I, Sehitoglu H, Chumlyakov YI, Maier HJ. The role of nitrogen on the deformation response of hadfield steel single crystals. Metall Mater Trans A $2003 ; 34: 1821-31$.

[54] Renard K, Jacques PJ. On the relationship between work hardening and twinning rate in TWIP steels. Mater Sci Eng A 2012;542:8-14. doi:10.1016/j.msea.2012.01.123.

[55] Li N, Wang YD, Lin Peng R, Sun X, Liaw PK, Wu GL, et al. Localized amorphism after high-strain-rate deformation in TWIP steel. Acta Mater 2011;59:6369-77. doi:10.1016/j.actamat.2011.06.048. 
[56] García TE, Rodríguez C, Belzunce FJ, Peñuelas I, Arroyo B. Development of a methodology to study the hydrogen embrittlement of steels by means of the small punch test. Mater Sci Eng A 2015;626:342-51. doi:10.1016/j.msea.2014.12.083.

[57] Hongo T, Edalati K, Iwaoka H, Arita M, Matsuda J, Akiba E, et al. High-pressure torsion of palladium: Hydrogen-induced softening and plasticity in ultrafine grains and hydrogen-induced hardening and embrittlement in coarse grains. Mater Sci Eng A 2014;618:1-8. doi:10.1016/j.msea.2014.08.074.

[58] Birnbaum HK, Sofronis P. Hydrogen enhanced localized plasticity-A mechanism for hydrogen related fracture. Mater Sci Eng A 1994;176:191-202.

[59] Wang S, Hashimoto N, Ohnuki S. Effects of hydrogen on activation volume and density of mobile dislocations in iron-based alloy. Mater Sci Eng A 2013;562:101-8. doi:10.1016/j.msea.2012.10.100.

[60] Glage A, Weigelt C, Räthel J, Biermann H. Fatigue behaviour of hot pressed austenitic TWIP steel and TWIP steel/Mg-PSZ composite materials. Int J Fatigue 2014;65:9-17. doi:10.1016/j.ijfatigue.2013.11.025.

[61] Reyes-Calderon F, Mejia I, Boulaajaj A, Cabrera J. Effect of microalloying elements $(\mathrm{Nb}, \mathrm{V}$ and $\mathrm{Ti}$ ) on the hot flow behavior of high-Mn austenitic twinning induced plasticity (TWIP) steel 2013;560:552-60. doi:10.1016/j.msea.2012.09.101.

[62] Yen H, Huang M, Scott CP, Yang J. Interactions between deformation-induced defects and carbides in a vanadium-containing TWIP steel. Scr Mater 2012;66:1018-23. doi:10.1016/j.scriptamat.2012.02.002.

[63] Jin J-E, Lee Y-K. Effects of Al on microstructure and tensile properties of C-bearing high Mn TWIP steel. Acta Mater 2012;60:1680-8. doi:10.1016/j.actamat.2011.12.004. 
[64] Hong S, Lee J, Lee B, Seop H, Kim S, Chin K, et al. Effects of intergranular carbide precipitation on delayed fracture behavior in three TWinning Induced Plasticity (TWIP) steels. Mater Sci Eng A 2013;587:85-99. doi:10.1016/j.msea.2013.08.063.

[65] Robertson IM. The effect of hydrogen on dislocation dynamics. Eng Fract Mech 2001;68:671-92.

[66] Sofronis P, Liang Y, Aravas N. Hydrogen induced shear localization of the plastic flow in metals and alloys. Eur J Mech - A/Solids 2001;20:857-72. doi:10.1016/S09977538(01)01179-2.

[67] Ulmer DG, Altstetter CJ. Hydrogen-induced strain localization and failure of austenitic stainless steels at high hydrogen concentrations. Acta Metall 1991;39:1237-48.

[68] Du YA, Ismer L, Rogal J, Hickel T, Neugebauer J, Drautz R. First-principles study on the interaction of $\mathrm{H}$ interstitials with grain boundaries in $\alpha$ - and $\gamma$-Fe. Phys Rev B Condens Matter Mater Phys 2011;84:1-13. doi:10.1103/PhysRevB.84.144121.

[69] Saito H, Miyazawa K, Ishida Y. Tritium Transmission Electron Microscopic Autoradiography of Hydrogen Trapping Sites at Interfaces in an Austenitic Stainless Steel SUS316L. J Japan Inst Met 1991;55:366-75.

[70] Koyama M, Bashir A, Rohwerder M, Merzlikin S V., Akiyama E, Tsuzaki K, et al. Spatially and Kinetically Resolved Mapping of Hydrogen in a Twinning-Induced Plasticity Steel by Use of Scanning Kelvin Probe Force Microscopy. J Electrochem Soc 2015;162:C638-47. doi:10.1149/2.0131512jes.

[71] Canadinc D. PhD Thesis. University of Illinois at Urbana-Champaign, USA, 2005.

[72] Allain S, Chateau JP, Bouaziz O. A physical model of the twinning-induced plasticity 
effect in a high manganese austenitic steel. Mater Sci Eng A 2004;387-389:143-7. doi:10.1016/j.msea.2004.01.060.

[73] Barbier D, Favier V, Bolle B. Modeling the deformation textures and microstructural evolutions of a Fe $-\mathrm{Mn}-\mathrm{C}$ TWIP steel during tensile and shear testing. Mater Sci Eng A 2012;540:212-25. doi:10.1016/j.msea.2012.01.128. 